\title{
Devulcanization of Waste Tire Rubber Using Amine Based Solvents and Ultrasonic Energy
}

\author{
Rashmi Walvekar ${ }^{1 *}$, Zulkefly Mohammad. Afiq ${ }^{1}$, Suganti Ramarad $^{2}$, and Siddiqui Khalid $^{3}$ \\ ${ }^{1 .}$ School of Engineering, Taylor's University, 47500 Subang Jaya, Selangor, Malaysia \\ 2. School of engineering and physical sciences, Heriot Watt University Malaysia, 62200 Putrajaya, \\ Malaysia \\ 3. Graphene \& Advanced 2D Materials Research Group (GAMRG), Research Centre for Nano- \\ materials and Energy Technology (RCNMET), School of Science and Technology, Sunway \\ University, No. 5, Jalan Universiti, Bandar Sunway, 47500 Subang Jaya, Selangor, Malaysia
}

\begin{abstract}
This research project focuses on an alternative pathway of devulcanizing waste tire rubber by using amine based chemicals. Waste tire rubbers are known to be as toxic, non-degradable material due to their vulcanized crosslink carbon structure, and disposing of such waste could impose hazardous impacts on the environment. The current rubber recycling methods that are practiced today are rather uneconomical, nonenvironmentally friendly, and also producing recycled rubber with low quality due to the alteration in the main polymeric chains of waste rubber. This project aims to answer the question of whether the usage of amine can produce high quality rubber, where the properties of recycled rubber is almost the same as new/virgin rubber. With known potential of amine, it is a challenge for the chemical to selectively cleave the sulfur bonds without affecting the main carbon backbone chain in the rubber structure and diminishing much of the rubber properties. To study this research, aminetreated rubber must undergo devulcanisation process by applying heat and sonication energy. Then, the properties of the amine-treated rubber were determined through a set of characterization tests and analysis which are: gel content test to determine the weight of rubber before and after devulcanization, the thermogravimetric analysis (TGA) to determine the thermal degradation and stability of rubber, and Fourier Transform Infrared Spectroscopy (FTIR) to determine any structural change of the rubber. In this research so far, the first two preliminary analysis tests have been performed. The gel content test has shown that tertiary amine samples possessed a lower gel content (\%) of (77 - $63 \%)$, compared to primary amine samples (falls within the range of $80 \%$ ), as well as the TGA test in which tertiary amine samples degrade faster than primary amine samples (suggesting a higher degree of rubber structure breakdown). For each type of amine, the concertation of amine did not play a major role in affecting the degree of devulcanization (as the concentration increased, the degree of devulcanization decreased for some samples). FTIR analysis showed that only sulphur-sulphur bonds were cleaved during the devulcanization process, leaving the carbon-sulphur bonds unaffected.
\end{abstract}

\footnotetext{
${ }^{1}$ Corresponding author: rashmi.walvekar@gmail.com
} 


\section{Introduction}

Rubber is an elastomer with a potential to return to its original state when deformed. External conditions (such as external force), the structure and the molar mass of the rubber are factors which can influence the deformation rate of rubber. Usually, rubbers possess regular and long macromolecule chains which can restore their initial position once the external deforming forces are removed. There are natural rubbers and synthetic rubbers used in industrial applications. Natural rubbers are usually obtained from a plant called Hevea Brasiliensis, while synthetic rubbers are mainly derived by constructional polyreactions of chain or grade nature [1]. For rubber to be used in commercial purposes, raw rubber is required to undergo treatment processes in order to increase the rubber's strength and life. Treatment processes of rubber may involve the addition and mixing of the rubber with industrial oils, additives, and carbon black filler [2].

Vulcanization is a curing process which transforms the rubber into a strong, elastic, and rubbery hard state. This process involves the crosslinking of rubber macromolecules which results in the foundation of three dimensional network of rubber matrix as shown in Figure 1 [1]. This network pattern makes the rubber more durable and stronger which contributes to improved wear and durability of the rubber [2].

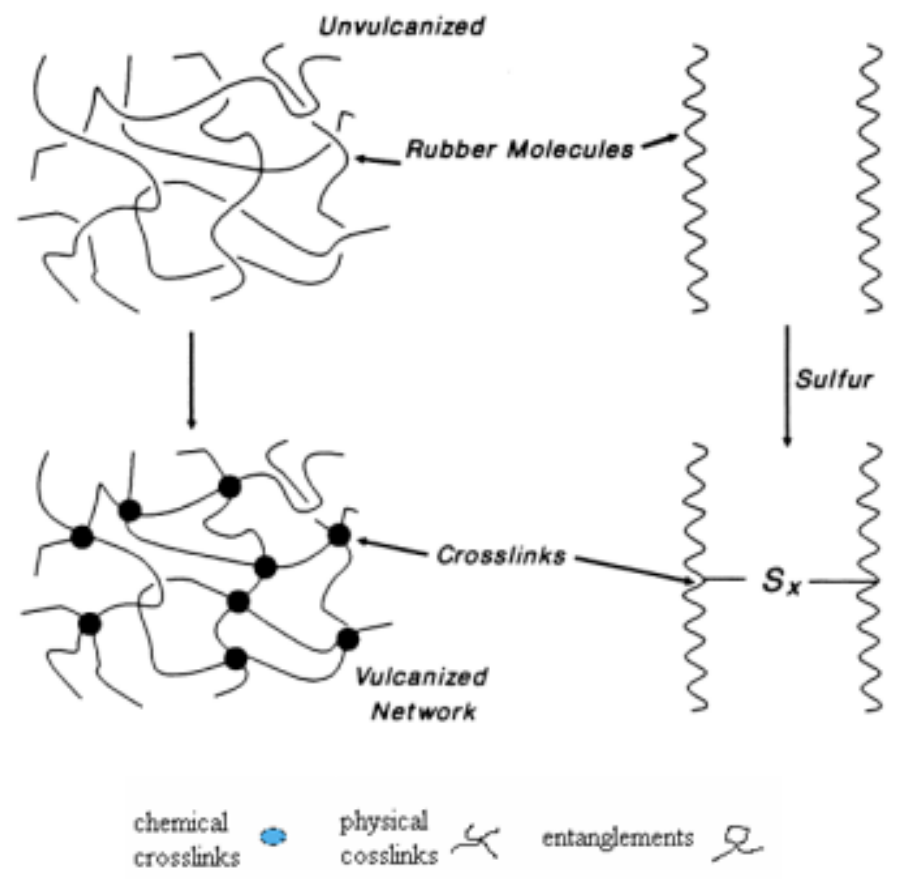

Fig. 1. Three dimensional rubber matrix [1].

Different types of chemical-based crosslinking agents, such as peroxides, sulfur, metal oxides, and resins, are involved in the process of rubber macromolecules crosslinking formation. These agents are able to react with suitable functional rubber groups and to create cross-links between them. Typical composition of car and lorry tires are shown in Table 1 below. Out of all these agents, sulfur remains the most successful and economical 
cross linking agent even today. This is due to the fact that sulfur is low in toxicity and cost, compatible with other additives, and able to predictably provide the desired vulcanisation properties. The typical vulcanisation system consists mainly of sulfur, metal oxide (usually zinc oxide), a fatty acid (to make the metal oxide soluble), and one or more organic accelerators, where the chemical reaction between sulfur and the rubber hydrocarbon occurs mainly at the $\mathrm{C}=\mathrm{C}$ (double bonds) [3]. Vulcanization is generally considered irreversible. In other words, after it has been altered, the once long, complex, and twisted rubber molecule cannot return to its original form [3].

Table 1: Composition of a tire [4].

\begin{tabular}{|c|c|c|c|}
\hline & Ingredient & Passenger Car Tire & Lorry Tire \\
\hline stromers & Rubber/Ela & $41-48 \%$ & $41-45 \%$ \\
\hline black & Carbon & $22-28 \%$ & $20-28 \%$ \\
\hline & Metal & $13-16 \%$ & $20-27 \%$ \\
\hline & Textile & $4-6 \%$ & $0-10 \%$ \\
\hline & Zinc Oxide & $1 \%$ & $2 \%$ \\
\hline & Sulphur & $1 \%$ & $1 \%$ \\
\hline & Additives & $10-12 \%$ & $7-10 \%$ \\
\hline
\end{tabular}

Tires produced by vulcanization are non-degradable material, which means that they could potentially stick around indefinitely. It is estimated that over 250 million tires are discarded annually. The amount of discarded waste tire rubber around the world is increasing at an alarming rate and only a small part of these wastes is recycled. The remaining are either buried, landfilled or stockpiled [4]. The disposal area of the tires contributes to the reduction of biodiversity since tires release toxic components to the environment. Tires are also very susceptible to be burned when subjected to high temperature. Once they are ignited, they will release toxic fumes and produce oil that will eventually contaminate soil and water [5]. Waste tires could also pose a threat to the humans by becoming a home ground for rodents and mosquitos that are responsible for carrying many types of disease [6]. Hence, the recycling of rubber wastes is vital in order to maintain a safe and healthy environment.

Although the rubber industry has a long time experience dealing with rubber, the perfect solution for disposal and recycling method for rubber products is yet to be found. Devulcanization is a technique where the crosslink structure, specifically the S-S and/or C$\mathrm{S}$ bonds are cleaved. This can be done by various methods such as mechano-chemical, chemical, biological, and using ultrasonic energy, which are available and practiced today [7]. Common current scission processes of S-S and S-C bonds are demonstrated in Figure 2.

However, the optimum efficiency of devulcanization is yet to be discovered as the current existing processes produce uncontrolled polymer rubber chain degradation, where the breakage of main macromolecule ( $\mathrm{C}-\mathrm{C}$ bonds) could occur. In actuality, the breakage of $\mathrm{C}-\mathrm{C}$ bonds is called a reclamation process. So in light of this, the current physical or chemical processes of converting used rubber into reusable form should be called reclamation rather than devulcanisation. Currently, when used rubber is recycled through any one of the existing processes, the main polymer chain ( $\mathrm{C}-\mathrm{C}$ bonds) is broken, leading to poor mechanical properties due to structural changes, where the rubber cannot be reused or re-vulcanized [8]. A proper devulcanisation process should only involve the cleavage of the $\mathrm{S}-\mathrm{S}$ and/or C-S bonds, which basically means the reverse process of vulcanization, where 
the devulcanizates resemble the original material in quality and structure (high quality rubber).

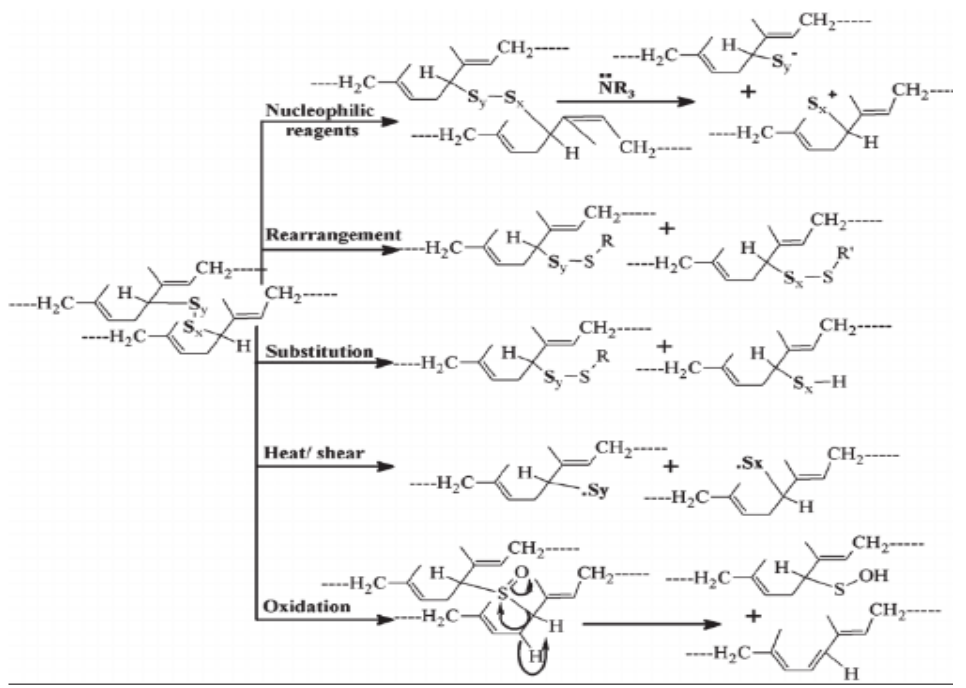

Fig. 2. General principles of current devulcanization processes [9].

Today, finding and developing a more selective breakdown process in recycling used rubber is a global challenge. Some of the latest works where the introduction of amine usage as an alternative to devulcanise rubber have been initiated. Several types of amine function as degradation stabilizers for coatings and plastics. Most degradation processes such as devulcanization at high temperature, would have a free radical character, where amine could facilitate in the process reaction by serving as radical scavengers [10]. Works performed by Verbruggen et al. [10], show that amines (eg. Primary, secondary, and tertiary) could be an effective devulcanization agent. This may be due to the ability of amines to reduce the crosslink density mainly by selective reaction with sulfur bridges known as nucleophilic reaction. Figure below demonstrates the reaction of amine with rubber crosslinks.

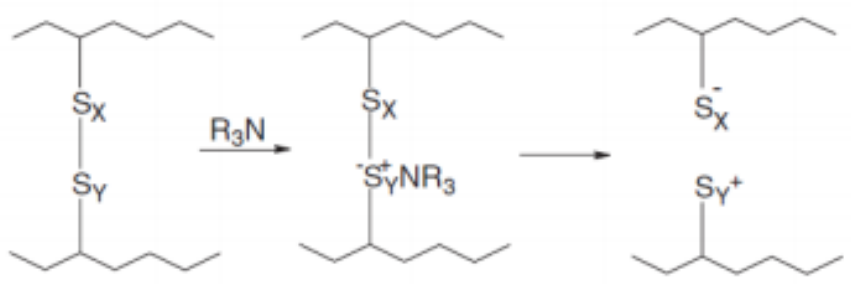

Fig. 3. Amine reaction with sulphur crosslinks [11].

As such, in this research, the devulcanisation of waste tire rubber in the presence of amine to produce high quality recycled rubber is studied. Different conditions will be performed to aid the devulcanisation process, which includes varying temperature and also by sonication radiation as these two are the most effective commercial techniques. Thus, this study aims to compare the effect of different types of amines on the degree of rubber devulcanization and to assess the effect of amine concentration on the degree of rubber devulcanization.

\section{Methodology}


Quantitative research approach was applied where analysis was done based on experimental data that was collected along the way. This involved the process of analyzing the degree of devulcanization where the amount of sulfur removed was studied based on the experimental and numerical results.

\subsection{Amine Preparation}

Two types of amines, which are primary [(3-AminoPropylTrimethoxysilane), $\mathrm{C}_{6} \mathrm{H}_{17} \mathrm{NO}_{3} \mathrm{Si}$ ] and tertiary [(n-Diethyl-3-AminoPropyl) Trimethoxysilane), $\mathrm{C}_{10} \mathrm{H}_{2} 5 \mathrm{NO}_{3} \mathrm{Si}$ ] amines, were bought from Nano Life Quest Sdn. Bhd. and used as the de-vulcanizing agent for ground waste tire rubber. To compare the effect of concentrations, the primary amine was prepared at three different concentrations while the tertiary amine was prepared at two different concentrations based on molarity, where at each concentration of amine, the sample was mixed with $50 \mathrm{ml}$ of water as base. Every amine sample was then added to $20 \mathrm{~g}$ of ground waste tire rubber. In this study, the different in concentrations were referred to as different in R:A ratio. Based on preliminary study, the ratios of the amount of rubber to amine are as follows:

Table 2: Rubber (R) to Amine (A) ratio for Primary Amine.

\begin{tabular}{|c|c|c|}
\hline R:A ratio & Amount of Rubber & Amine Volume \\
\hline $1: 0.5$ & $20 \mathrm{~g}$ & $10 \mathrm{ml}$ \\
\hline $1: 0.25$ & $20 \mathrm{~g}$ & $5 \mathrm{ml}$ \\
\hline $1: 0.125$ & $20 \mathrm{~g}$ & $2.5 \mathrm{ml}$ \\
\hline
\end{tabular}

Table 3: Rubber (R) to Amine (A) ratio for Tertiary Amine.

\begin{tabular}{|c|c|c|}
\hline R:A ratio & Amount of Rubber & Amine Volume \\
\hline $1: 0.25$ & $20 \mathrm{~g}$ & $5 \mathrm{ml}$ \\
\hline $1: 0.125$ & $20 \mathrm{~g}$ & $2.5 \mathrm{ml}$ \\
\hline
\end{tabular}

On top of that, two types of control samples were also prepared as to compare the results after the devulcanization process. One solely contains rubber and the other contains a mixture of rubber and $50 \mathrm{ml}$ of water, as to investigate if water would play a part in the devulcanization process.

\subsection{Devulcanization Process and Rubber Sample Preparation}

After the preparations of amine and rubber samples were done, the next step was to perform the devulcanization process. In this stage, every sample prepared in Schott bottle was allowed to experience and undergo the ultrasonication process. In this study, three variables were fixed; they were the sonication time and sonication frequency. In addition to that, another two variables were varied; they were the sonication temperature, and the rubber to amine ration, as shown in Table 6 and 7 for primary and tertiary amine, respectively.

One reason of why amine was chosen was because of the fact that amine is known to be an agent, suitable for desulphurization processes [12], and assumed to possess the same ability for the process of devulcanization. According to, an acceptable heating treatment for rubber, for it to not have any effects on the main polymer chain (carbon-carbon bonds), is within the range of 130 to $180^{\circ} \mathrm{C}$. The heating treatment in this devulcanization process was paired together with the sonication. Since amines were involved during the process of devulcanization, the temperature chosen must be at or lower than $80^{\circ} \mathrm{C}$ as the boiling point of the primary amine used, is at $80^{\circ} \mathrm{C}$. On top of that, since the ultrasonic water bath was used, temperatures lower than $100^{\circ} \mathrm{C}$ were decided on.

The temperatures chosen to be the heating environment during the sonication were 30,50 and $80^{\circ} \mathrm{C}$, while the sonication frequency of $37 \mathrm{~Hz}$ was also chosen as the Ultrasonic water bath equipment was only limited to this frequency. In addition to that, $37 \mathrm{~Hz}$ was also selected as the 
sonication frequency was because of the fact that it is the optimum condition with minimum degradation of rubber properties, according to Suganti R. et al. [13]. Due to safety purposes, the experiment was conducted at a pressure of $1 \mathrm{~atm}$.

Varying temperatures and applying a frequency of $37 \mathrm{~Hz}$ were expected to agitate the rubber crosslink structure and weaken the Sulphur bonds, in order to allow the amine to penetrate through the crosslink structure. Since there were three different set temperatures, each rubber to amine ratio would then have three replications so that one rubber to amine ratio sample would experience different temperature than the other samples in the same ratio. The number of samples are summarized in Tables 4, 5 and 6.

Table 4: Rubber control samples.

\begin{tabular}{|c|c|c|c|}
\hline $\begin{array}{c}\text { Sonication } \\
\text { Temperature }\left({ }^{\circ} \mathrm{C}\right)\end{array}$ & $\begin{array}{c}\text { Amount of Rubber } \\
\text { (grams) }\end{array}$ & $\begin{array}{c}\text { Amount of Water } \\
(\mathrm{mL})\end{array}$ & Sample Number \\
\hline 30 & \multirow[t]{6}{*}{20} & \multirow[t]{3}{*}{-} & 1 \\
\hline 50 & & & 2 \\
\hline 80 & & & 3 \\
\hline 30 & & \multirow[t]{3}{*}{50} & 4 \\
\hline 50 & & & 5 \\
\hline 80 & & & 6 \\
\hline
\end{tabular}

Table 5: Primary Amine Samples.

\begin{tabular}{|c|c|c|c|c|}
\hline R:A ratio & $\begin{array}{c}\text { Sonication } \\
\text { Temperature } \\
\left({ }^{\circ} \mathrm{C}\right)\end{array}$ & $\begin{array}{c}\text { Amount of } \\
\text { Rubber } \\
\text { (grams) }\end{array}$ & $\begin{array}{c}\text { Amine } \\
\text { Volume }(\mathrm{mL})\end{array}$ & $\begin{array}{c}\text { Sample } \\
\text { Number }\end{array}$ \\
\hline \multirow[t]{3}{*}{$1: 0.5$} & 30 & \multirow[t]{9}{*}{20} & \multirow[t]{3}{*}{10} & 7 \\
\hline & 50 & & & 8 \\
\hline & 80 & & & 9 \\
\hline \multirow[t]{3}{*}{$1: 0.25$} & 30 & & \multirow[t]{3}{*}{5} & 10 \\
\hline & 50 & & & 11 \\
\hline & 80 & & & 12 \\
\hline \multirow[t]{3}{*}{$1: 0.125$} & 30 & & \multirow[t]{3}{*}{2.5} & 13 \\
\hline & 50 & & & 14 \\
\hline & 80 & & & 15 \\
\hline
\end{tabular}

Table 6: Tertiary Amine Samples.

\begin{tabular}{|c|c|c|c|c|}
\hline R:A ratio & $\begin{array}{c}\text { Sonication } \\
\text { Temperature } \\
\left({ }^{\circ} \mathrm{C}\right)\end{array}$ & $\begin{array}{c}\text { Amount of } \\
\text { Rubber } \\
\text { (grams) }\end{array}$ & $\begin{array}{c}\text { Amine } \\
\text { Volume (mL) }\end{array}$ & $\begin{array}{l}\text { Sample } \\
\text { Number }\end{array}$ \\
\hline \multirow[t]{3}{*}{$1: 0.25$} & 30 & \multirow[t]{6}{*}{20} & \multirow[t]{3}{*}{5} & 16 \\
\hline & 50 & & & 17 \\
\hline & 80 & & & 18 \\
\hline \multirow[t]{3}{*}{$1: 0.125$} & 30 & & \multirow[t]{3}{*}{2.5} & 19 \\
\hline & 50 & & & 20 \\
\hline & 80 & & & 21 \\
\hline
\end{tabular}


As shown in the tables above, there are a total of 21 samples including the control samples. Each devulcanization process (application of $37 \mathrm{~Hz}$ sonication frequency in the respective temperature) took place for 15 minutes. Afterwards, the rubber from every sample was then filtered out by using the gravity filtration method [14]. Then, every sample was washed thoroughly by using distilled water at least three times to ensure no presence of amine in the rubber samples. Lastly, the washed rubber was then dried in the oven at $70^{\circ} \mathrm{C}$ for a period of 24 hours, to ensure minimum to none moisture content present in rubber samples, before characterization can take place.

\subsection{Rubber Characterization}

Characterization of the rubber test samples was the next stage of this research. There were three different techniques in dealing with the determination of the amount of Sulphur removed in the rubber samples, they are: gel content test, thermogravimetric analysis (TGA), and Fourier Transform Infrared Spectroscopy (FTIR).

\subsubsection{Gel Content Test}

The gel content test samples were determined according to ASTM D2765. $0.2 \pm 0.05 \mathrm{~g}$ of every rubber sample was measured and placed in a stainless steel wire mesh pouch of 120 mesh size. Three pouches were ready from each sample in order to attain an average result. In order to dissolve the soluble content, the samples placed in wire mesh were extracted in boiling toluene by using a Soxhlet apparatus for 24 hours. Then, test samples were collected and dried in an oven for 24 hourse at $70^{\circ} \mathrm{C}$ until a constant mass is achieved. The gel content was then calculated by using the following Eq. (1) [13].

Gel content $(\%)=\frac{w_{1}}{w_{0}} \times 100$

Where $\mathrm{w}_{0}$ is the weight of dried sample before extraction and $\mathrm{w}_{1}$ is the weight of dried sample after extraction. The soluble content was calculated by using the following Eq. (2):

Soluble $\%=100-$ Gel content $(\%)$

\subsubsection{Thermogravimetric Analysis (TGA)}

TGA was responsible for the determination of the test samples' thermal degradation and stability. This was done by utilizing a computerised thermo gravimetric analyser (Perkin Elmer - TGA 8000). To assess the thermal stability, dynamic TGA experiments was carried out. Rubber sample, weighted around 5 to $10 \mathrm{mg}$ was placed on a sample pan before placing it in the instrument. The experiment was conducted by heating the samples from room temperature up to a temperature of $600^{\circ} \mathrm{C}$ to collect the weight loss vs temperature thermogram. Every analysis was done with test samples in Nitrogen atmosphere (with flow rate of $20 \mathrm{ml} / \mathrm{min}$ ) with a rate of heating of $10^{\circ} \mathrm{C} / \mathrm{min}$. Before analysis can be done, a leastsquares averaging technique was used to smoothen out the curve of normalised weight loss vs temperature. $\mathrm{T}_{\max }$ was denoted as the temperature at the maximum rate of weight loss. $\mathrm{T}_{\max }$ will be identified from the peak of the derivative (dW/dT) curve, where $\mathrm{W}$ is weight loss and $\mathrm{T}$ is temperature. With all these temperatures, they then was referred to and used to determine the thermal degradation and stability of the test samples $[15,16]$. 


\subsubsection{Fourier Transform Infrared Spectroscopy}

This method allows the evaluation of any structural change on the rubber based on which bonds are broken after the devulcanization process. Data analysis can be done based on the graphs generated by FTIR (Perkin Elmer FTIR Spectrum 100). ATR method was used for this FTIR analysis. As aforementioned, waste tire rubber with and without the help of amine as the devulanizing agent during devulcanization were examined in order to detect the degree of devulcanization.

This test analysis involved the testing of control samples and rubber samples with amine, in order to observe and detect if amine would actually impose any additional impacts in cleaving the sulphur bonds, reducing the crosslink structure of rubber during the devulcanization process. In addition to that, studies on which other bonds or compounds were removed during the devulcanization and comparisons between different samples can be made, which can be done by identifying the spectra produced.

\section{Results and Discussion}

As per discussed previously, the first preliminary stage of screening the rubber samples involved two tests which are: gel content test and thermogravimetric analysis (TGA).

\subsection{Gel Content Test Analysis}

Figure 4 shows the average gel content value for every sample at three different sonication temperatures. The results obtained portray an irregular pattern as it does not have a proper trend. At $30^{\circ} \mathrm{C}$ sonication temperature, all of seven samples fall within the range of 75 to $88 \%$ of gel content.

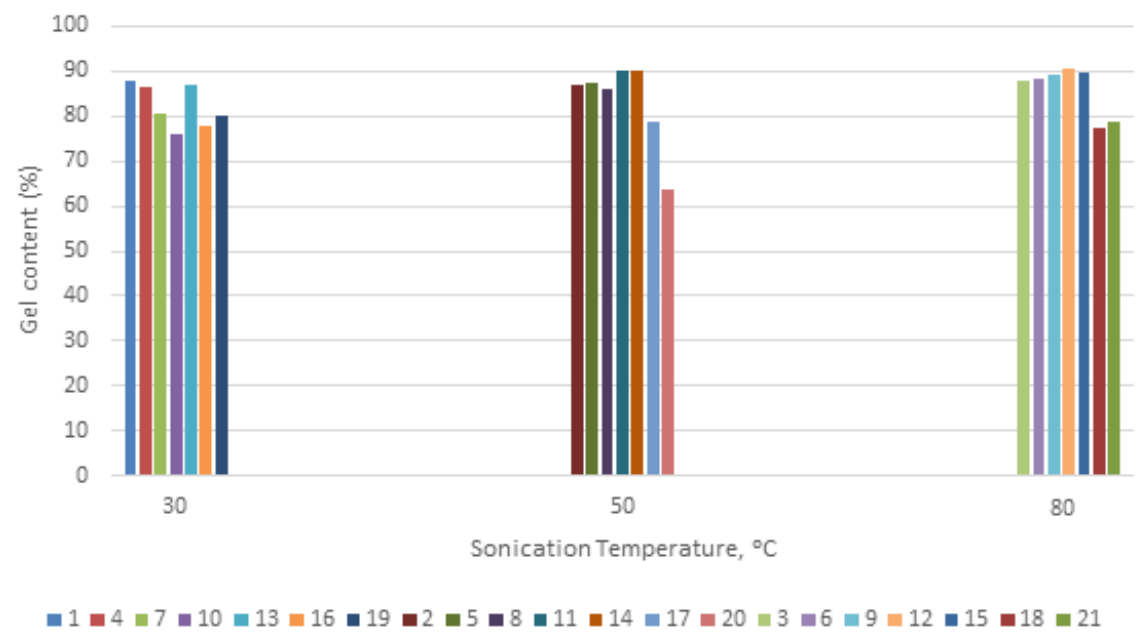

Fig.4. Gel content of rubber samples at different sonication temperature.

It is common for rubber to show gel content between $50 \%$ and $90 \%$ due to the presence of crosslinked structure of molecules. This can be seen from the control samples $1-6$. The sonication temperature has a little effect on the gel content of rubber as all control samples 
project gel content $\%$ that is almost similar in value. However, at $30^{\circ} \mathrm{C}$, as $10 \mathrm{ml}$ of primary amine was added into sample 7 , the gel content decreased in value from 87 to $80 \%$, which shows that amine had an effect in aiding the breakdown of the rubber structure. As the amine volume was decreased to $5 \mathrm{ml}$ in sample 10, the gel content however decreased even more up to $75 \%$. However, when the amine concentration was further decreased to $2.5 \mathrm{ml}$ in sample 13, the gel content shows a value of that near the control sample.

A feasible explanation to this results is that, as the amount of amine concentration decreases, it could become more reactive relative to the amount of rubber in one sample. When the concentration was further decreased, the sulphur bonds could have been reformed leading to the higher gel content. The results also show that as the temperature of sonication was increased, it did not have much effect of the degree of crosslinked structure cleavage. This can be seen for instance, from samples 7,8 and 9. The gel content tend to increase rather than decrease with an increase in temperature. One explanation to this occurrence is that, the primary amine's boiling temperature used in this experiment, is at $80^{\circ} \mathrm{C}$. Increasing the sonication temperature higher near to its boiling point, may have agitated the amine too much, leading it to evaporate, and leaving no chemicals left to aid in the process of cleaving sulphur bonds through nucleophilic reaction. This may have been a factor influencing the efficiency of the devulcanization, as the temperature was increased. This can be seen from the increasing pattern of gel content in every rubber to amine ratio samples, as the temperature was increased. In addition to that, according to [4], the acceptable temperature where the crosslinked structure would be reduced effectively is within the range of 130 to $180^{\circ} \mathrm{C}$. This shows that the involved heating treatment in the ultrasonicator was not sufficient to break down the rubber structure.

Similarly, tertiary amine results also portray an irregular pattern. However, the gel content analysis shows that the gel content of rubber which was treated by tertiary amine was lesser than those treated by primary amine. The gel content was managed to be reduced and has an average range of 77 to $63 \%$. The most effective treatment was observed from sample 20 , in which the rubber was treated by $2.5 \mathrm{ml}$ of tertiary amine and heated at $50^{\circ} \mathrm{C}$ during the sonication process.

Based on Figure 4, Samples 16, 17 and 18 display an almost the same amount of gel content, even all these three samples were under different temperatures using the heating and sonication treatments. This results may have been due to the uneven distribution of amine in all samples or unequal distribution of rubber particle during the process of devulcanization. On top of that, it may have also have been because of the discrepancies in the mixture of rubber sample composition. On the other hand, the results show that the gel content decreased in value to $63 \%$ as the temperature was increased to $50^{\circ} \mathrm{C}$, and increased back to around $78 \%$ as the temperature increased to $80^{\circ} \mathrm{C}$. This result shows that the efficiency of tertiary amine in helping breaking down the crosslink structure of rubber increased to a certain temperature, in this case was $50^{\circ} \mathrm{C}$, and would decrease when the temperature was further increased to $80^{\circ} \mathrm{C}$. The increase of gel content from sample 20 to 21 , must have been due to the reformation of sulphur bonds with the main backbone chain, as the amine failed to capture the free radicals during the devulcanization process.

The results from this gel content experiment show that tertiary amine was more effective and reactive towards breaking down the rubber structure than the primary amine. This is contrary to the initial expectation as primary amine is usually more reactive than tertiary amine. 


\subsection{Thermal Analysis}

High temperature TGA $\left(30-600^{\circ} \mathrm{C}\right)$ plots of samples $1,4,7,10,13$ and 19 are shown in Figure 5. Based on Figure 12, all TGA plots show a one-step degradation. Different degradation temperatures calculated from Figure 5 can be seen in Table 7.

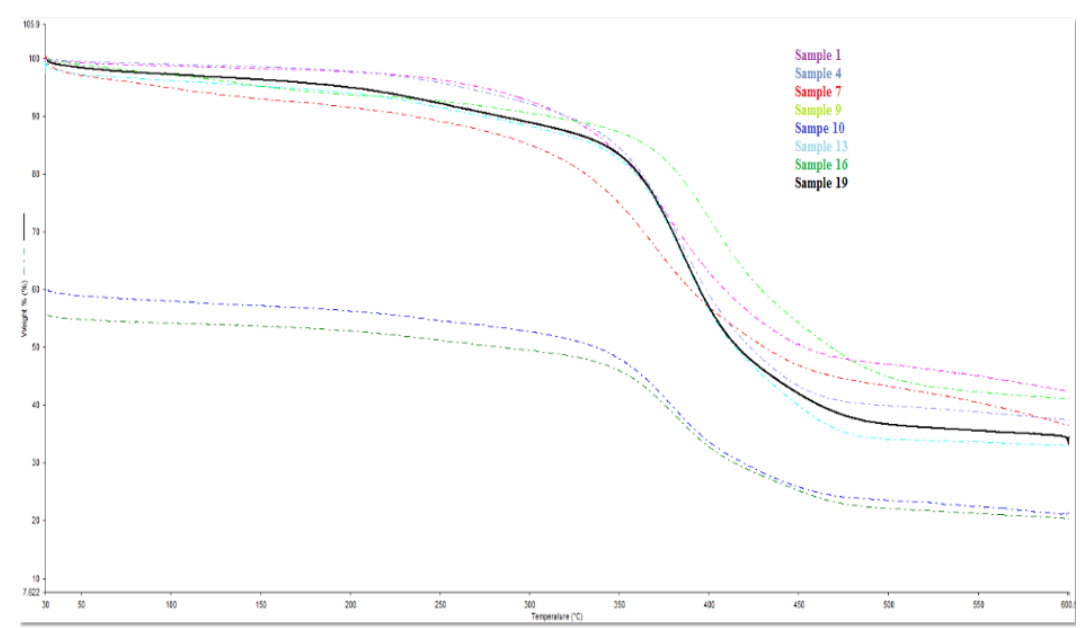

Fig.5. TGA plots of Samples 1, 4, 7, 9, 10, 13, 16, and 19.

Table 7: TGA parameters

\begin{tabular}{|c|c|c|c|}
\hline Sample Number & $\left.\mathbf{T}_{\mathbf{1}}{ }^{\mathbf{}} \mathbf{C}\right)$ & $\mathbf{T}_{\mathbf{4 0}}\left({ }^{\circ} \mathbf{C}\right)$ & $\mathbf{T}_{\mathbf{8 0}}\left({ }^{\circ} \mathbf{C}\right)$ \\
\hline 1 & 333.96 & 408.18 & 496.09 \\
\hline 4 & 349.58 & 398.62 & 494.26 \\
\hline 7 & 325.59 & 389.73 & 439.50 \\
\hline 8 & 363.25 & 387.87 & 440.13 \\
\hline 9 & 371.12 & 401.72 & 468.13 \\
\hline 13 & 357.71 & 393.85 & 448.97 \\
\hline 19 & 349.58 & 394.96 & 460.54 \\
\hline
\end{tabular}

Based on Table 7, the onset degradation $\left(T_{1}\right)$ of the control sample 4 started at $349.58^{\circ} \mathrm{C}$. Forty percent degradation $\left(\mathrm{T}_{40}\right)$ and $80 \%$ degradation of the same control sample started at 398.62 and $494.26^{\circ} \mathrm{C}$ respectively. For the sample which was treated with primary amine, sample number 7 , the onset degradation $\left(\mathrm{T}_{1}\right)$ occurred at lower temperature $\left(325.59^{\circ} \mathrm{C}\right)$. The $\mathrm{T}_{40}$ and $\mathrm{T}_{80}$ of sample 7 occurred at 389.73 and $439.50^{\circ} \mathrm{C}$ respectively. For the sample which was treated with a lower primary amine concentration, sample number 13 , the onset degradation $\left(\mathrm{T}_{1}\right)$ occurred at higher temperature $\left(357.71^{\circ} \mathrm{C}\right)$. The $\mathrm{T}_{40}$ and $\mathrm{T}_{80}$ of sample 13 occurred at 393.85 and $448.97^{\circ} \mathrm{C}$ respectively. For the sample which was treated with tertiary amine, sample number 19 , the onset degradation $\left(\mathrm{T}_{1}\right)$ occurred at a slightly lower temperature $\left(349.58^{\circ} \mathrm{C}\right)$. The $\mathrm{T}_{40}$ and $\mathrm{T}_{80}$ of sample 7 occurred at 394.96 and $460.54^{\circ} \mathrm{C}$ respectively.

The delayed degradation of control sample 4 compared to sample 7 suggested that the treated sample 7 with the devulcanizing agent had a cross-linking structure breakdown 
due to the presence of amine. The control sample 4 was more stable towards thermal degradation because of the extra-cross-linking due to the absence of a devulcanizing agent during the devulcanization process. Cross-linking increased the rigidity of the system, which in turn increased the thermal stability. When the primary amine had a lower concentration as in sample 13, the rubber took longer to degrade, in comparison to sample 7. As discussed in the previous analysis section, this may due to the reformation of Sulphur bonds, which lead to a stronger crosslinked structure.

Based on Table 7, Sample 8, which was treated with primary amine at a sonication temperature of $50^{\circ} \mathrm{C}$ had an onset degradation $\left(\mathrm{T}_{1}\right)$ which occurred at temperature $\left(363.25^{\circ} \mathrm{C}\right)$. The $\mathrm{T}_{40}$ and $\mathrm{T}_{80}$ of sample 8 occurred at 387.87 and $440.13^{\circ} \mathrm{C}$ respectively. For the sample which was also treated with primary amine, but at a higher sonication temperature of $80^{\circ} \mathrm{C}$, sample number 9 , the onset degradation $\left(\mathrm{T}_{1}\right)$ occurred at higher temperature $\left(371.12^{\circ} \mathrm{C}\right)$. The $\mathrm{T}_{40}$ and $\mathrm{T}_{80}$ of sample 9 occurred at 401.72 and $468.13^{\circ} \mathrm{C}$ respectively. This is an indication of a more rigid structure of sample 9 compared to 8 , and sample 8 compared to sample 7 . As previously discussed, the gel content of sample 9 is the highest due to the amine evaporated from the rubber samples. Hence, it took sample 9 the longest for it to be degraded.

On top of that, sample 19 was treated with the same amine volume as sample 13 , and it showed a lower degradation temperature than sample 13. This data also tallied with the gel content analysis, portraying that the tertiary amine had helped more in the reduction of rubber crosslinked structure than the primary amine.

\subsection{Fourier Transform Infrared Spectroscopy (FTIR) Analysis}

Based on Figure 6 above, it can be observed that the peaks for sulphur-sulphur bonds (in the range of 700-550 cm-1 and carbon-sulphur bonds (in the range of 720-570 cm-1) still exist based on the peaks generated from the plot. This means that during the devulcanization process, the sonication energy at a frequency of $37 \mathrm{~Hz}$ and at three different temperatures did not possess enough energy to cleave the sulphur bonds. It also means that water did not perform any additional effects on the rubber structure during the devulcanization process. Though there is some variation in graph patterns for devulcanization at different temperature environment, lines A and B marked on the graph still indicate that the sulphur bonds still exist in the rubber structure. 


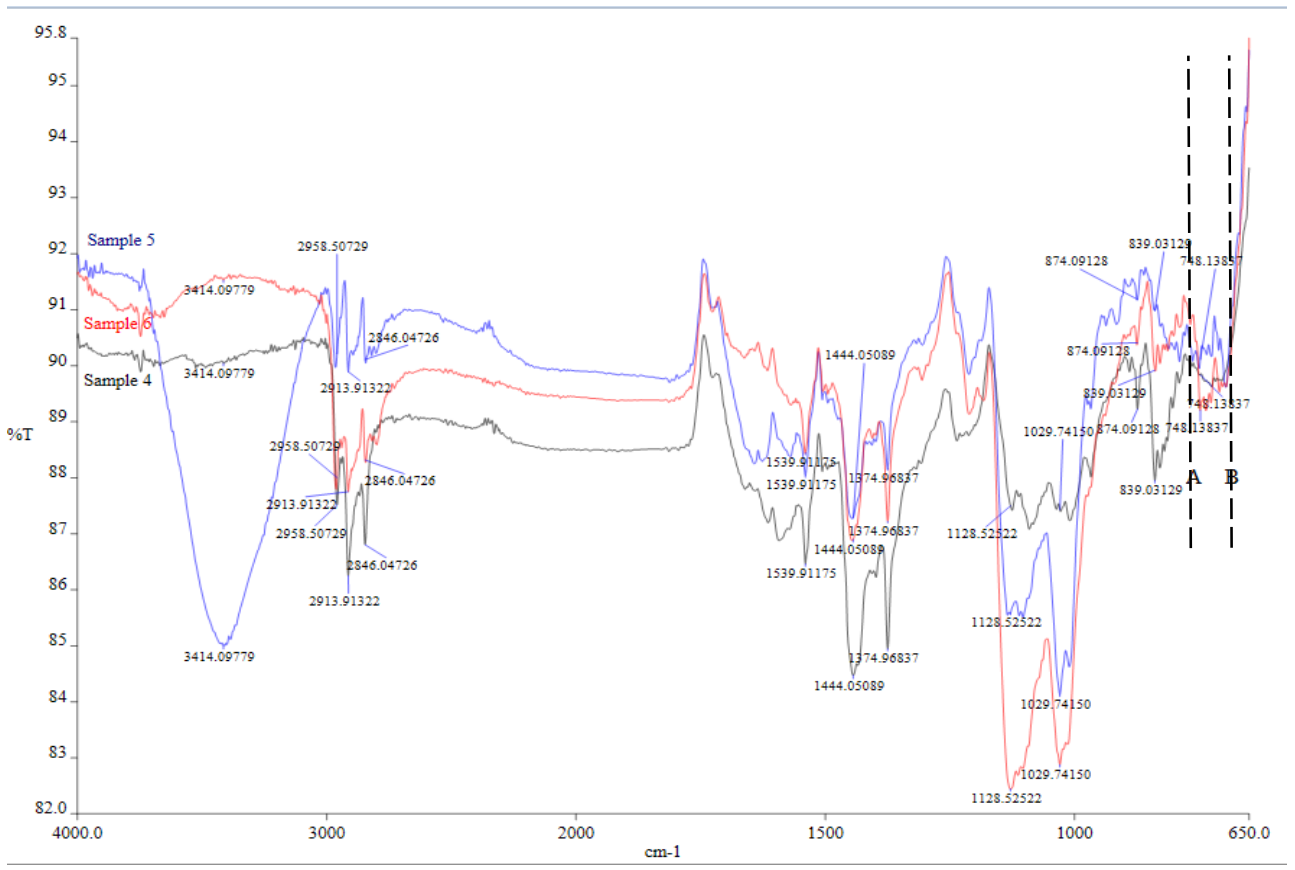

Fig.6. Plots of control samples 4,5 and 6 (with $50 \mathrm{ml}$ of water)

Based on Figure 7(a),(b), and, (d) lines A and B represent the regions for carbonsulphur bonds and sulphur-sulphur bonds respectively. As seen from the plots, it can be seen that sulphur bonds are still present even with after going through devulcanization with the presence of primary amine. From Figure 7(a), where the amine concentration is the largest, at rubber to amine ratio of 1:0.5, there seems to be an increasing pattern in sulphursuphur bonds. That is, the peaks seem to be appearing as the sonication temperature was increased, from Samples 7 to 9. This is an indication that the at higher the sonication temperature, the less effective the amine is to cleave the sulphur bonds. This may due to the fact that as the temperature increases to $80^{\circ} \mathrm{C}$ the amine must have evaporated slowly out of the rubber mixture, as the boiling temperature of the primary amine used is $80^{\circ} \mathrm{C}$. Similarly, for the other two rubber to amine ratio, as the data presented in Figures 7(b) and (d), the sulphur-sulphur bonds tend to be more in terms of amount, as the sonication temperature increased. This pattern can be seen from Samples 10 to 12 in Figure 7(b), for rubber to amine ratio of 1:0.25, and Samples 13 to 15 in Figure 7(d), for amine ratio of 1.0.125. The explanation to this is may also be to the fact that as the temperature increases, it gets near to the primary amine's boiling temperature. Hence, the amount of amine to allow more cleavage of sulphur bonds would be less, and devulcanization becomes less effective. On top of that, there is no indication of carbon-sulphur bonds cleavage throughout the curves for the samples. This is an indication of the energy exerted on the rubber samples were not strong enough to break the carbon-sulphur bonds. 


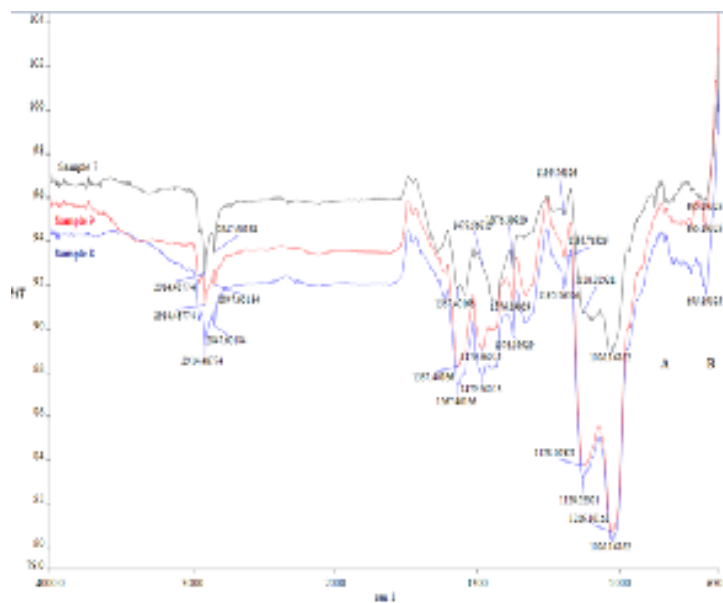

(a)

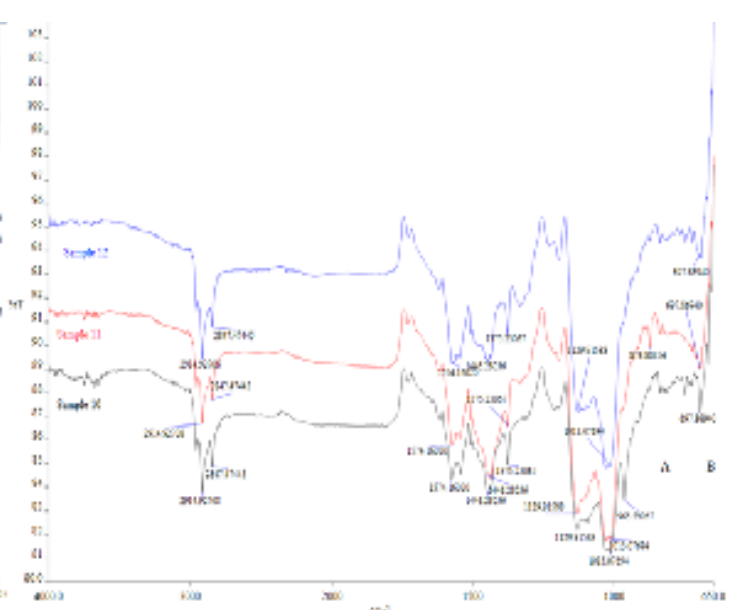

(b)

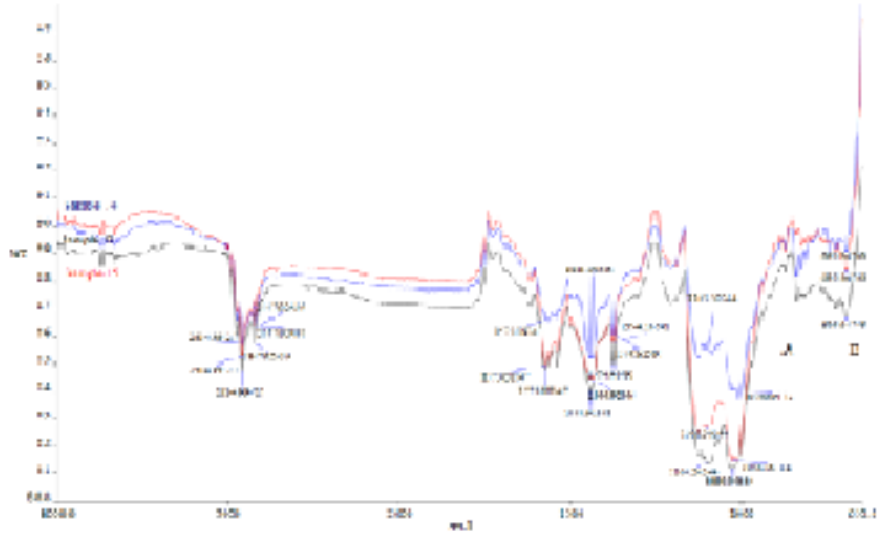

(d)

Fig.7. FTIR plots for primary amine, R:A of 1:0.5 (a), 1:0.25 (b), \& 1:0.125 (d)

These results show that primary amine helps in breaking sulphur bonds to a certain degree, when compared to the results of primary amine to the control samples. The energy was sufficient enough to break sulphur-sulphur bonds, but not carbon-sulphur bonds as carbon-sulphur bonds would require higher energy to be broken. However, the findings also show that, the effectiveness of primary amine decreases as the temperature increases. This may due to the fact that, the primary amine may have escaped as the temperature gets higher, near to its boiling temperature, which leads to the lower efficiency of devulcanization

Based on Figure 8(a) and (b) the curves shown are the results generated for tertiary amine at rubber to amine ratio of 1:0.25 and 1:0.125 respectively. Samples 16, 17 and 18 curves marked at B, show an even distribution of plots, which may indicate that the amount of sulphur-sulphur bonds existing in these three samples may be almost the same. This explains as why these rubber samples possess almost the same amount of gel/soluble fraction, as previously recorded in the gel content test. Based on Sample 19 plot from the Figure $8(\mathrm{~b})$, there seems to be some sulphur-sulphur bonds marked in the region B. But the peaks seem to be disappearing in Sample 20, which indicates the disappearing of sulphursulphur bonds in Sample 20. However, the peaks reappear in Sample 21, which indicates 
the reformation of sulphur bonds as the sonication temperature increases. The explanation to this phenomenon is that, as the temperature increases, the tertiary amine participated in the process of cleaving the sulphur-sulphur bonds even more as it gets more excited. However, after some time, the sulphur bonds tend to reappear which shows that to a certain degree, when the temperature increases, the sulphur bonds tend to reform and adhere back to the rubber structure. These results may enhance the findings from the gel content test analysis where from Sample 19 to 20, the gel fraction tends to decrease. While it increases from Sample 20 to 21. Similarly, the carbon-sulphur bonds during this treatment were unaffected, which can be seen from the peaks in the graphs. Indicating that the energy applied onto the rubber was not sufficient enough to break the chain.

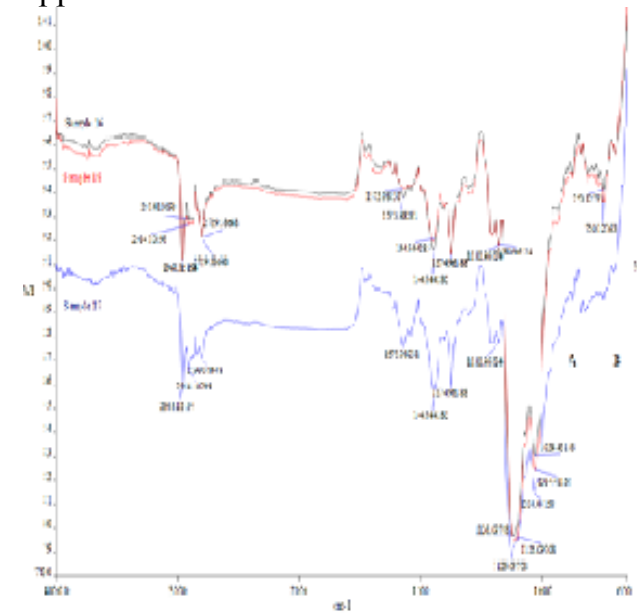

(a)

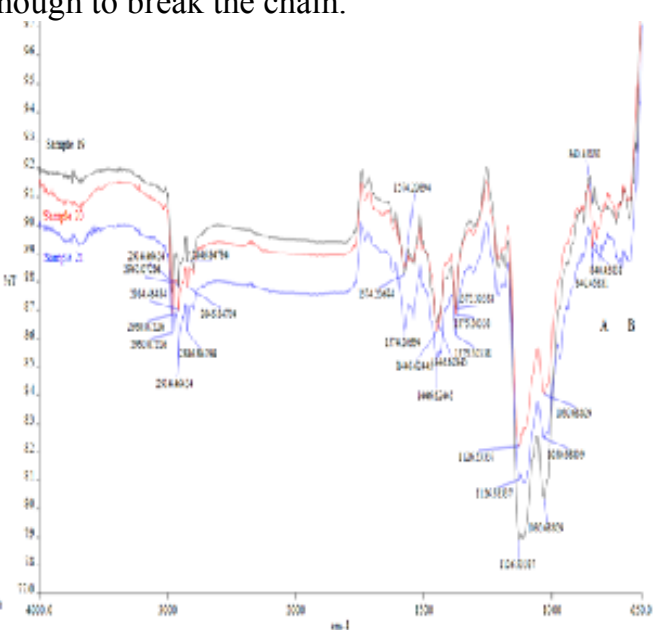

(b)

Fig.8. FTIR plots for tertiary amine, R:A of 1:0.25 (a) and 1:0.125 (b)

Based on all the FTIR figures shown previously, the control samples are the only samples which generated some peaks beyond the range of 3000 and $1700 \mathrm{~cm}-1$, which may indicate the presence of water remained in the samples. These peaks are not observed in all the other FTIR curves for any amine + rubber samples. This is an indication that there is a small degradation of bonds containing groups $-\mathrm{OH}$ and $-\mathrm{C}=\mathrm{O}[17]$.

In conclusion, both types of amines could undergo nucleophilic reaction, due to the existence of free radicals during the process of devulcanization. Both types of amines were capable of only cleaving sulphur-sulphur bonds, where tertiary amine showed a more promising result than primary amine. The efficiency of primary amine was compromised, because of the high sonication temperature which was near to its boiling temperature. In addition to that, no other bonds were broken as there was not enough energy to break them. The main carbon backbone chain was not affected during the dvulcanization process, which is an indication of if, the devulcanized rubber were to be vulcanized, it could result in rubber with good physical property.

\section{Conclusion}


Based on the preliminary tests, the usage of amine as the devulcanizing agent, coupled with heating and sonication treatments has shown that there is a structural change in the rubber structure. However, the degree of structural breakdown is not substantial. One of the factors may be due to the fact that the devulcanizing environment, such as temperature, is not sufficient to encourage the scission of the Sulphur bonds in the rubber crosslinked structure. Amine is able to undergo the nucleophilic reaction, but only to a certain extent. As oppose to the previous expected outcome, these two analysis tests have proven that tertiary amine is more efficient in breaking down rubber structure than the primary amine. This is proven by the gel content test which has shown a lower gel content $(\%)$ of $(77-63 \%)$, compared to primary amine samples (falls within the range of $80 \%$ ), as well as the TGA test in which tertiary amine samples degrade faster than primary amine samples (suggesting a higher degree of rubber structure breakdown).

The effects of amine concentration were difficult to be studied as the results generated did not have a regular pattern, as the sonication temperature also played a role during the process of devulcanization within the 15 minutes timeframe. However, the results have portrayed that the higher the concentration of amine is, the higher the breakdown of structure takes place. However, for some types of amine such as tertiary, under a certain condition, the lower the concentration is, the higher the degree of devulcanization. This can be seen from sample 20, with rubber to amine ratio of 1:0.125, had a more structural breakdown than sample 17, whose rubber to amine ratio was 1:0.25. Hence, amine may have the capacity to cause crosslinked structure breakdown of rubber, but it still may not be efficient enough to be used on industrial levels

\section{References}

1. J. A. Brydson "Rubber Chemistry," pp. 194-205, 1978.

[2] T. Liang et al., "Continuous Devulcanization of Ground Tire Rubber of Different Particle Sizes Using an Ultrasonic Twin-Screw Extruder," pp 200-230, 2013.

[3] G. S. Whitby and H. E. Simmons, "Vulcanization Accelerators-I.," Ind. Eng. Chem., vol. 17, no. 9, pp. 931-935, 1925.

[4] S. Ramarad, M. Khalid, C. T. Ratnam, A. L. Chuah, and W. Rashmi, "Waste tire rubber in polymer blends: A review on the evolution, properties and future," Prog. Mater. Sci., vol. 72, no. March, pp. 100-140, 2015.

[5] F. P. Torgal, A. Shasavandi, and S. Jalali, "Tyre Rubber Wastes Based Concrete: A review," WASTES Solut. Treat. Oppor., p. 3, 2011.

[6] Rinkesh, "Tire Recycling," Conserv. Energy Futur., 2015.

[7] M. Hess, H. Geisler, and R. H. Schuster, "Devulcanization as an opportunity to recycle rubber," Chem. List., vol. 103, no. 13, 2009.

[8] S. Seghar et al., "Devulcanization of styrene butadiene rubber by microwave energy: Effect of the presence of ionic liquid," Express Polym. Lett., vol. 9, no. 12, pp. 1076-1086, 2015.

[9] J. Anu Mary, G. Benny, K. N. Madhusoodanan, and A. Rosamma, 
"The current status of sulphur vulcanization and devulcanization chemistry: devulcanization," Rubber Sci., vol. 29, no. 1, pp. 62-100, 2016.

[10] P. Sutanto et al., "Development of a Continuous Process for EPDM Devulcanization in an Extruder," p. 124, 2006.

[11] S. Saiwari et al., "Post-consumer tires back into new tires: devulcanization and re-utilization of passenger car tires". 2013.

[12] A. Bocoum, S. Hosseinnezhad, and E. Fini, "Investigating effect of amine based additives on asphalt rubber rheological properties," Asph. Pavements, no. September, pp. 921-931, 2014.

[13] S. Ramarad, C. T. Ratnam, M. Khalid, A. L. Chuah, and S. Hanson, "Improved crystallinity and dynamic mechanical properties of reclaimed waste tire rubber/EVA blends under the influence of electron beam irradiation," Radiat. Phys. Chem., vol. 130, pp. 362370, 2017.

[14] Univeristy of calgary, "Filtration Methods, Organic Laboratory Techniques," pp. 1-5, 2012.

[15] W. J. Sichina, "Characterization of Polymers Using TGA," pp. 1-5, 2000.

[16] ASTM International, "Standard Test Method for Compositional Analysis by Thermogravimetry," vol. i, no. C, pp. 9-13, 2012.

[17] S. Rodsuk, S. Ritsuar, and K. Wattanakul, "Characterization the effect of disulfide compound on the devulcanization of thermoplastic vulcanizate," AIP Conf. Proc., vol. 1482, pp. 240-245, 2012. 